\title{
Reviewing the sports coach mentoring literature: A look back to take a step forward
}

Thomas M. Leeder ${ }^{\text {a* }}$ and Rebecca Sawiuk ${ }^{\mathrm{b}}$

${ }^{a}$ School of Sport, Rehabilitation and Exercise Sciences, University of Essex, Colchester, $U K$

${ }^{\mathrm{b}}$ School of Life and Medical Sciences, University of Hertfordshire, Hatfield, Herts, UK

*Corresponding author. Thomas M. Leeder, School of Sport, Rehabilitation and Exercise Sciences, University of Essex, Colchester, CO4 3SQ, UK. Email:

thomas.leeder@essex.ac.uk https://orcid.org/0000-0002-7456-2175

Rebecca Sawiuk: r.sawiuk@herts.ac.uk @Sav_RK89 orcid.org/0000-0001-9487-9930

Word Count: 9020 


\section{Reviewing the sports coach mentoring literature: A look back to take a step forward}

This article takes a look back, in order to take a step forward, for sports coach mentorship within both academia and practice. Consequently, this article aims to review the contemporary trends within the sports coach mentoring literature and beyond to build upon earlier foundations. Throughout, four areas of significance are identified: (1) A sociocultural analysis of sports coach mentorship; (2) multiple-mentors and developmental networks; (3) developing sports coach mentors; and (4) gender and role models. The existing literature within each area is introduced, analysed, and critiqued, before an innovative future research agenda is established. Whilst mentorship is regularly utilised within sports coaching, the practice remains undertheorised and conceptually vague. Therefore, this literature review attempts to reconstruct sports coach mentorship by highlighting gaps in our knowledge and instigating innovative research agendas to produce contextually and culturally bound empirical evidence. Thus, this article advances our understanding of mentoring practice within sports coaching.

Keywords: multi-mentoring, literature review, coach development, mentorship, coach learning 


\section{Introduction}

2 Mentoring is a practice which operates across various domains, yet suffers from a lack of

3 conceptual clarity, with no universal definition currently present (Dawson, 2014;

4 Lefebvre, Bloom, \& Loughead, 2020). Mentoring's implementation across an array of

5 social contexts has contributed towards the practice remaining contested and ill-defined

6 (Colley, 2003; Dawson, 2014), with it being acknowledged that mentoring is "used

7 differently in different settings and for different purposes" (Kemmis, Heikkinen,

8 Fransson, Aspfors, \& Edwards-Groves, 2014, p. 155). Despite its contested nature,

9 mentoring has generally been considered a dynamic and reciprocal relationship between

10 a mentor (advanced knowledge and experience) and a protégé (a mentee who is seeking

11 new knowledge and experience) to enhance career development (Newby \& Heide, 2013).

12 Thus, mentoring is typically perceived as a process of support, with a more

13 knowledgeable 'other' facilitating the development of a neophyte practitioner. Indeed, it

14 is suggested that learners who are mentored by a more experienced individual become

15 open to an array of psychosocial and career development benefits, including enhanced

16 self-confidence, increased professional competence, and accelerated career progression

17 (Kram, 1985; Newby \& Heide, 2013). Consequently, mentoring has been adopted as a

18 professional learning strategy for practitioners across health care, education, and business

19 domains (Lefebvre et al., 2020), with organisations using the practice as a "vehicle for

20 handing down knowledge, maintaining culture, supporting talent, and securing future

21 leadership" (Darwin, 2000, p. 197). Indeed, the associated value of mentoring combined

22 with its potential to situate learning in context has seemingly led to the inclusion of, and

23 advocation for, mentoring programmes within sports coaching (Bloom, 2013; Fraina \&

24 Hodge, 2020). 
1 practitioner supporting the professional learning and practice of a less experienced coach

2 (Nash \& McQuade, 2015). Recently, the sports coaching field has encountered a 3 rhetorical 'rush to mentoring' (Bailey, Jones, \& Allison, 2019), with literature that 4 explores sports coach mentorship steadily increasing (e.g. Bloom, 2013; Chambers, 2015, 5 2018). In shaping the research landscape on sports coach mentorship, the seminal 6 literature review by Jones, Harris, and Miles (2009) is significant. Within this review, the 7 authors explored empirical evidence on mentoring across varying disciplines, whilst 8 offering tentative suggestions towards developing effective sports coach mentorship. In 9 concluding their review, Jones et al. (2009, p. 276) proposed that sports coach mentoring 10 literature lacks conceptual clarity and argued that future research should begin to critically 11 explore "the dilemmas and nuances of mentoring relationships so that superficial, one12 dimensional accounts are avoided". Over a decade on, there remains a need to build upon 13 Jones and colleagues' (2009) work, by exploring and understanding the contemporary 14 trends within the sports coach mentoring literature.

Research since 2010 has tended to portray mentoring as a solution for the 16 professional development of coaches due to its ability to provide contextualised learning, 17 which overcomes some traditional critiques of coach education (Cushion, 2015; Griffiths, 18 2015). Mentoring is a pedagogical approach which supports the experiential learning of 19 sports coaches (Nash \& McQuade, 2015), with learning from 'experience' playing a significant role in coach development (Cushion, Armour, \& Jones, 2003; Groom \&

21 Sawiuk, 2018; Lyle \& Cushion, 2017). Therefore, mentoring has been advocated as a 22 method of harnessing the influential power of experience through guidance, observation, 23 and reflective practice, allowing coaches to become better equipped to deal with the 24 uncertain nature of coaching (Cushion, 2015; Cushion et al., 2003). 
Sports coach mentoring can be conceptualised as formal or informal in nature. As

2 proposed by Cushion (2015), informal mentoring is frequent and ongoing, referring to

3 observations and interactions with other coaching practitioners, without oversight from

4 an organisation. Alternatively, formal mentoring programmes are often controlled by

5 Governing Bodies (GBs), where dyadic mentorships are structured and monitored

6 through the obtainment of objectives (Sawiuk, Taylor, \& Groom, 2018). However, it is

7 important to acknowledge mentoring is a social process involving interactions,

8 interdependence, and the interests of a range of stakeholders (Cushion, 2015). As Potrac

9 (2016) explains, the mentoring process entails various stakeholders, including mentors,

10 mentees, GBs (if formalised), clubs, athletes, and parents. Thus, mentoring practice does

11 not operate in a social, political, or technological vacuum. Such an acknowledgment has

12 underpinned the recent reconceptualisation of mentoring beyond dyadic relationships, to

13 include possessing multiple-mentors (Sawiuk, Taylor, \& Groom, 2017), developmental

14 networks, involving all people who provide support (Higgins \& Kram, 2001), and e-

15 mentoring via technology (Grant, Bloom, \& Lefebvre, 2020).

For over 20 years, the coach learning literature has depicted mentorship as one of

17 the most meaningful formal or informal 'learning situations' coaches engage with.

18 Indeed, research seeking to understand the learning journeys of coaches has frequently

19 highlighted the value of mentors at different developmental stages (e.g. Bloom et al.,

20 1998; Fairhurst, Bloom, \& Harvey, 2017). Thus, it would appear mentorship, in one form

21 or another, is generally regarded as positive for coach development. Yet, research which

22 simply presents sports coach mentorship as straightforward, benign, and always

23 beneficial for sports coaches should be challenged, as it fails to capture the true

24 complexities and realities of practice (Cushion, 2015). Whilst mentoring is frequently

25 conceptualised as either a formal or informal 'learning situation' for coaches, the wider 
1 nuances of mentorship (e.g. mentor behaviours, development of rapport) within the coach

2 learning process are often overlooked. For example, how mentee coaches 'filter'

3 information from their mentor and choose to either adopt, adapt, or reject new knowledge

4 within mentorship is generally unknown (Stodter \& Cushion, 2017), despite trust, respect,

5 and organisational beliefs, amongst other factors, likely to influence the process (Jones et

6 al., 2009; Leeder \& Cushion, 2019). Moreover, research has tended to neglect mentor

7 biographies, recruitment, and training, often assuming expert coaches naturally possess

8 all the attributes of an effective mentor (e.g. Bloom et al., 1998; Chambers, 2015).

Jones et al. (2009) strived to eliminate some of the conceptual 'fog' and provide

10 enhanced clarity regarding sports coach mentorship. Yet, we are still struggling to

11 reconstruct and imagine what transformative mentoring practice for coaches entails

12 (Bailey et al., 2019), justifying the need to take a reflective look back to take steps forward

13 for sports coach mentorship. Recently, Lefebvre and colleagues (2020) utilised a novel

14 citation network analysis to ascertain how scholars utilise career mentoring literature

15 from wider disciplines to inform sports coach mentoring research. In concluding their

16 analysis, the authors highlighted three research agendas for sports coaching: alternative

17 mentoring models; marginalised groups; and formal mentoring. However, we believe

18 contemporary research has to some extent addressed these areas, for example alternative

19 mentoring approaches (Grant et al., 2020; Sawiuk et al., 2017), marginalised groups

20 (Banwell, Stirling, \& Kerr, 2019; Fairhurst et al., 2017; Sawiuk \& Groom, 2019), and

21 formal mentoring (Leeder \& Cushion, 2019; Sawiuk et al., 2018; Zehntner \& McMahon, 22 2019).

Thus, this article aims to review contemporary trends within the sports coach 24 mentoring literature and beyond to update Jones and colleagues' (2009) work, whilst identifying four areas of significance. These four areas are: (1) A sociocultural analysis 
1 of sports coach mentorship; (2) multiple-mentors and developmental networks; (3)

2 developing sports coach mentors; and (4) gender and role models. The existing literature

3 within each area is introduced, analysed, and critiqued, before an innovative future

4 research agenda is established.

\section{Sports coach mentorship: A sociocultural analysis}

\section{The sociocultural foundations of mentoring}

7 Sports coaching is frequently understood as a social process, where an interaction of

8 macro and micro elements influences how the practice is perceived and enacted (Lyle \&

9 Cushion, 2017). Similarly, mentoring practice within sports coaching will be shaped by

10 social structures, trends, and power relationships (Cushion, 2015). Perhaps most

11 predominantly, the influence of social structures, political agendas, and power can be

12 evidenced through the formalisation of sports coach mentoring (Sawiuk et al., 2018).

13 Here, a GB will adopt a structured approach to mentoring by establishing objectives,

14 highlighting key practices, matching mentors and mentees, and delivering training

15 (Cushion, 2015; Sawiuk et al., 2018). Problematically, formalised mentoring is often

16 situated within institutional frameworks, inclusive of narrow learning outcomes, with

17 external interests influencing the process (Sawiuk et al., 2018).

Formalised sports coach mentoring generally involves episodic, in-situ observations of coaching practice, enabling bespoke coach learning to occur (Cushion, 2015). However, a mentor's observations are likely to be informed by institutional agendas, potentially associated with perceived coaching workforce demographic needs, qualification targets, and prescriptive coaching models (Sawiuk \& Groom, 2019). Therefore, questioning the effectiveness of formalised sports coach mentoring appears rational (Trudel \& Gilbert, 2006). Since Jones and colleagues' (2009) review, several empirical studies informed by sociological theory, specifically Pierre Bourdieu and 
1 Michel Foucault, have critically analysed formalised sports coach mentoring. These

2 studies have attempted to outline the inherent nuances and tensions, to help deconstruct

3 mentoring practice and problematise taken-for-granted assumptions (Lyle \& Cushion,

4 2017). The benign nature of sports coach mentoring is challenged, presenting the practice

5 as relational, contested, and as a system of power which can reproduce differences and

6 normative beliefs (Cushion, 2015).

\section{$7 \quad$ Formalised sports coach mentoring: A Bourdieusian analysis}

8 The use of Pierre Bourdieu's praxeology has been adopted to understand mentoring as an

9 embodied and social (re)productive practice within various coaching domains. Griffiths

10 and Armour (2012) examined formalised mentoring as a learning strategy for volunteer

11 sports coaches by looking to understand how a group of coaches and mentors engaged in,

12 and made sense of, the mentoring process. In drawing upon Bourdieu (1990), mentoring

13 practice was outlined as a complex, ambiguous, and developmentally staged learning

14 process, underpinned by volunteerism. It is proposed that meaningful interactions within

15 mentoring are mediated by context (fields), where the habitus of volunteer coaches is

16 shaped and re-shaped, with their learning impacted by dispositions, actions, and

17 interpretations (Griffiths \& Armour, 2012). These findings suggest that formalised sports

18 coach mentoring is contextually bound and influenced by organisational factors

19 (Griffiths, 2015).

Within elite coaching contexts, Sawiuk and colleagues' (2018) Bourdieusian analysis argued that formalised sports coach mentoring programmes could be

22 conceptualised as a form of social control, where organisational agendas override

23 meaningful coach learning. Due to a lack of capital, mentors were unable to challenge

24 the orthodox culture which prevails within their own sporting fields, undergoing a process

25 of misrecognition, uncritically accepting the arbitrary culture of their GB (Bourdieu, 
1 1990). Further challenges encompassed over-formalising the mentoring process and the

2 negative impact of micro-politics between the various stakeholders involved, alongside

3 funding and 'target hitting' tensions (Sawiuk et al., 2018).

4 More recently, Leeder and Cushion (2019) explored the extent that a GB's 5 coaching culture was reproduced through a formalised sports coach mentoring 6 programme, evidencing issues with external GB interests. Specifically, the coaching 7 culture was embodied by mentors during their training, before later being espoused and 8 reproduced during their mentoring practice. In short, the findings present formalised 9 sports coach mentoring as a source of cultural reproduction, where mentors attempted to 10 reshape the habitus of mentee coaches to align with the field's doxa (Bourdieu, 1990). 11 Having embodied the requisite dispositions, mentors promoted the organisation's 12 coaching culture to their mentees, which over time became internalised, influenced by 13 mentors' enhanced volumes of capital. Thus, in a similar manner to other Bourdieusian 14 inspired research (e.g. Griffiths \& Armour, 2012; Sawiuk et al., 2018), it would appear 15 that context and the entrenched cultures of varying fields, in addition to organisational 16 agendas, are significant in influencing mentoring practice and mentee learning.

17 Formalised sports coach mentoring: A Foucauldian analysis

18 As Cushion (2015) contends, mentoring is assumed to be positive, yet the practice is a 19 social construction, operating within distinct cultures involving power relations. Mentors 20 have the capacity to define what counts as legitimate knowledge, whilst potentially 21 reproducing organisational norms uncritically (Cushion, 2015; Leeder \& Cushion, 2019; 22 Sawiuk et al., 2018). Consequently, issues surrounding power-knowledge within the mentor-mentee relationship has led to a body of research informed by Michel Foucault. 
2 surveillance and power at work within mentorships in the Australian swimming culture.

3 In utilising autoethnography, it was argued mentor coaches act as mediators of the

4 organisation which employs them, utilising practices to encourage conformity and create

5 docile coaches (Foucault, 1979; Zehntner \& McMahon, 2014). Foucault's (1979)

6 concepts of hierarchical observation, normalising judgement, surveillance, and the

7 examination were adopted to present formalised sports coach mentoring as a system of

8 discipline, where mentors were used to ensure coaches subscribed to a normalised set of

9 behaviours (Zehntner \& McMahon, 2014). Zehntner and McMahon (2019) drew upon

10 Foucault's (1979) ideas surrounding disciplinary power and the panopticon to explore

11 mentee swim coaches' experiences of a formalised mentoring initiative embedded within

12 coach education. The findings mirror the lead author's own experiences, where power

13 was exercised through the mentoring programme to ensure mentees' coaching practice

14 conformed to social norms, creating a social climate where mentee learning and practice

15 were culturally constrained (Zehntner \& McMahon, 2019).

Alternatively, Leeder (2019a) drew upon Foucault's ideas surrounding pastoral

17 power to critically analyse formalised mentoring. Although not based on empirical data,

18 it is argued sports coach mentors act as officials of pastoral power, encouraging

19 confessional techniques for their mentees to adopt an inward gaze and self-examination

20 (Leeder, 2019a). Having acquired knowledge of their mentee's consciousness through a

21 subjectifying process, a mentor can mould their mentee's thoughts and behaviours

22 towards their organisation's agenda. From a Foucauldian stance, it would seem GBs may

23 adopt formalised sports coach mentoring provision to maintain their own interests,

24 seeking to reproduce uncritically accepted coaching ideologies (Leeder, 2019a; Zehntner

$25 \&$ McMahon, 2014, 2019). 


\section{$1 \quad$ Setting a new agenda: Researching formalised sports coach mentoring}

2 There remains limited evidence of successful formalised sports coach mentoring 3 programmes (Bailey et al., 2019). However, the studies highlighted within this section

4 have begun to problematise and challenge formalised mentoring's effectiveness. Bailey 5 and colleagues (2019) have recently called for mentors to support their mentees in 6 apprehending the social structures which influence coaching practice. However, before 7 this can occur, mentors need to adopt a critically reflexive stance and recognise the very 8 social structures and power relations which impact upon their own knowledge and 9 practice. Therefore, embracing sociological theories may prove useful in revealing the 10 tensions which exist between GB beliefs, power, and mentor dispositions, creating space 11 for the critical mentor whilst accounting for individual agency.

Future scholarly work should continue to disrupt dominant ways of thinking with

13 respect to formalising sports coach mentoring (Sawiuk, et al., 2018). Whilst 14 postmodern/poststructuralist approaches (Bourdieu, Foucault) have proved insightful, 15 perhaps researchers may wish to draw upon interpretive sociological frameworks (e.g. 16 Goffman, Garfinkel, Hochschild) to help understand the social and relational interactions 17 (Potrac, 2016), in addition to the construction of subjectivities, within sports coach 18 mentoring. Moreover, the application of wider pedagogical/learning theories (e.g. 19 behaviourism, cognitivism, social constructivism) or a focus on more intricate 20 interpersonal (e.g. trust), emotional, and micro-political tensions may help to present 21 sports coach mentoring as considerably more than a 'benign' activity (Cushion, 2015).

22 Furthermore, the use of inductive and primitive research approaches (e.g. grounded 23 theory) may appeal to scholars to help develop a distinct theorisation of mentoring which 24 can both inform and underpin policy and practice (Jones, 2019). 


\section{$1 \quad$ Moving beyond dyadic mentoring}

2 The field of sports coaching is playing catch up to the reconceptualisation of mentoring

3 within the broader literature, in that a mentee at the centre of either a multiple-mentor or

4 developmental network will experience different guidance, knowledge, and support from

5 each mentor (De Janasz \& Sullivan, 2004). The only empirical article to date to address

6 this issue within sports coaching is by Sawiuk et al. (2017), who highlighted how sports

7 coach mentors felt no single mentor could provide a mentee with all the answers. In part,

8 this argument provides an important justification for going beyond investigating

9 traditional dyadic mentorships. Subsequently, Higgins and Kram (2001), alongside De

10 Janasz and Sullivan (2004), have called for more scholarly attention into the concepts of

11 multiple-mentoring, developmental networks, and relationship constellations. Moreover,

12 the reconceptualisation coincides with the advancement of technology in the workplace,

13 with sports coaching and coach education following suit. As a result, mentoring in

14 practice might embed technology into the learning process (Higgins \& Kram 2001),

15 incorporating aspects of e-mentoring (Grant et al., 2020).

\section{Multiple-mentoring}

17 Multiple-mentoring was first discussed by Kram (1983), who proposed a mentee would 18 seek developmental support from multiple-mentors throughout their career. The concept

19 of multiple-mentoring suggests a mentee might receive "mentoring assistance from many

20 people at one point in time, including senior colleagues, peers, family and community

21 members" (Higgins \& Kram, 2001, p. 264). Multiple-mentoring is more effective than

22 dyadic mentoring, with the mentee benefitting from access to several skill and support

23 functions. This cluster of mentors can include individuals both inside and outside the

24 organisation (Baugh \& Scandura, 1999). Thus, the support these mentor types provide

25 might result in career advancement, higher organisational commitment, job satisfaction, 
1 less role conflict, or reduced desire to seek alternative employment (Baugh \& Scandura,

2 1999). Within the context of academia, early career mentees might need a mentor for a

3 specific skill (i.e. knowing why, how, or whom), whilst a second mentor may provide

4 role model or emotional support (De Janasz \& Sullivan, 2004). Moreover, De Janasz and

5 Sullivan (2004) suggest mentees might need to develop different competencies across

6 their career span, with a need to reflect upon the following questions: Is this what I want?

7 How do I attain the skills? Who can support me? Therefore, a 'mentor of the moment'

8 will provide personal support at the right time (Baugh \& Scandura, 1999). However,

9 mentors of the moment need to recognise when micro-politics, amongst other factors such

10 as 'gaps' in their own knowledge, may compromise the mentoring process.

Within the context of sports coaching, Sawiuk and colleagues (2017) reported mentoring relationships within formal programmes have begun to move beyond dyadic relationships towards multiple-mentors. For instance, a mentee might have access to a sport specific mentor and a mentor from a different sport or occupational domain. The work of Sawiuk and Groom (2019) features a contextual example, where a female mentee highlighted the importance of accessing the bespoke knowledge of multiple-mentors, which enabled her to become the best version of herself following practical experience and observations. Moreover, Sawiuk et al. (2017) drew on Kram's (1985) work and acknowledged how sports coach mentors were at times limited by their own knowledge and would need to effectively 'signpost' and think 'outside the box or outside the sport

21 itself' to provide meaningful learning experiences. Multiple-mentors can help combat

22 some of the micro-political problems within sport. For example, mentors using

23 'knowledge as a shield' or mentors perceived as 'spies', whereas mentors from another sport or outside of sport do not possess 'political baggage' (Sawiuk et al., 2017). Here, non-sport or cross-sport mentors were considered less threatening which enabled more 
1 trustworthy mentoring relationships to evolve. In sum, multiple-mentoring may reduce

2 the probability of dysfunctional mentoring.

\section{Developmental networks}

4 Developmental networks are increasingly commonplace within the mainstream 5 mentoring literature, originating from Kram's (1985) idea of a constellation of mentors. 6 Also, Higgins and Kram (2001) applied a theoretical network lens to mentoring, and

7 subsequently academic research on the concept of developmental networks began to 8 gather momentum (e.g. Higgins, Chandler, \& Kram, 2007). To date, only Sawiuk et al. 9 (2017) have discussed the nature and benefit of developmental networks within sports 10 coach mentoring, whilst calling for an increase in empirical research within this area. The 11 egocentric concept of a developmental network consists of "the set of people a protégé 12 names as taking an active interest in and action to advance the protégé's career by 13 providing developmental assistance" (Higgins \& Kram, 2001, p. 268). Figure 1 provides 14 an example of a developmental network structure:

16 These networks are subsets of a mentee's entire network or social capital, spanning 17 organisational boundaries and incorporating friends, family, and colleagues who provide 18 different forms and volumes of support (Higgins \& Kram, 2001; Higgins et al., 2007). It 19 is important to recognise that developmental networks differentiate from multiple20 mentors by acknowledging mentor-mentor relationships within the same network, namely tie density. Table 1 defines the characteristics of developmental networks. 
1 Developmental networks have become increasingly important for upward career

2 mobility, as the workplace is increasingly described as boundaryless (Higgins et al.,

3 2010). Therefore, a sports coach mentor from the same organisation as a mentee might

4 provide support regarding job role, advice on a colleague, contextualised organisational

5 (club) coaching dilemmas, expectations, culture, or philosophy. However, mentors from

6 outside the organisation have a reduced bias and are more likely to think about a mentee's

7 role objectively (Murphy \& Kram, 2014). Perhaps the concept of developmental networks

8 might help researchers to understand how coaches learn or advance their career in the

9 dynamic and chaotic environment of sports coaching.

Setting a new agenda: Researching multiple-mentoring and developmental networks

11 Sports coaching research on interpersonal relationships or the educational dimensions of

12 multi-mentor strategies is absent, with Sawiuk et al. (2017) calling for increased scholarly

13 attention on multiple-mentor and developmental networks mentorships. In part,

14 mainstream mentoring research can aid our thinking and practice (Lefebvre et al., 2020),

15 yet, within sports coaching we must create our own contextualised body of empirical

16 work. Mentoring in sport is a culturally and contextually bound activity, with aspects such

17 as 'credibility', 'technical knowledge', 'understanding the environment', and 'domain

18 specific knowledge' influencing the process (Sawiuk et al., 2018). Moving forward,

19 sports coaching scholars should consider the use of critical and self-reflexive research

20 methods, such as insider research (Wiser, 2018), autoethnography, and duo-

21 autoethnography or collaborative autoethnography (McMahon, 2016). These methods

22 will help to explore both mentors' and mentees' social norms or issues within personal

23 accounts of mentoring, as part of a constellation, to help facilitate dialogue and empathy

24 whilst influencing political and pedagogical practice. 
Additionally, within sports coach mentoring the answers derived from questions

2 such as Is this what I want? How do I attain necessary skills? Who can support me?

3 remain vague. A novice coach might require sport-specific knowledge, or perhaps first

4 aid, safeguarding, and athlete behaviour management guidance. A youth development

5 coach might seek advice on maturation or bio-banding, holistic coaching, pedagogy, or

6 technical detail, whilst an elite-level coach working with senior athletes may require

7 mentoring support with regards to micro-politics, media, leadership, recruitment, or

8 psychology. As a result, the longitudinal mapping of a mentee's or mentor's career

9 journey might help researchers to understand how the nature and type of mentoring

10 support evolves over a coach's career and impacts upon their career outcomes.

11 Furthermore, scholars within the field should consider how we could engage

12 critically with visual research methods, with the 'visual' being accepted as a central aspect

13 of contemporary social life. MacLaren's (2018) article on egocentric developmental

14 networks within nursing is particularly relevant, where mentoring constellations are

15 mapped out to demonstrate the viewpoint of different members of the constellation and

16 provide insight into tie strength, mutuality, and reciprocal mentorships. Visual methods,

17 perhaps via Gephi software, may 'open the door' for us to understand cultural

18 significance, social practices, trust, and power relations at a macro-level. Scholars might

19 want to consider researcher or participant photographs (Phoenix \& Rich, 2016), alongside

20 video diaries, e-learning platforms, webinars, blogs, social media, or video-based capture

21 of coaching delivery to align mentoring to the modernisation of technology. In sum, these

22 methodological approaches could enable researchers to engage with individual mentoring

23 experiences in an empathetic, participatory, and aesthetic manner.

\section{Developing sports coach mentors}


1 Within sports coaching, mentors rarely receive any form of professional development or

2 training (Chambers, 2018). This is problematic, as Nash and McQuade (2015, p. 212)

3 argue: "mentor learning and development is a vital component of any effective mentoring

4 programme". The lack of support available to sports coach mentors may relate to how the

5 practice is perceived, alongside assumptions about what a 'good' sports coach mentor

6 constitutes. Generally, mentoring is often treated as a secondary role for sports coaches,

7 a sometimes unwanted 'add on' to their primary profession of enhancing athlete

8 development (Chambers, 2018).

As facilitators of coach learning, sports coach mentors should be trained and

10 provided with ongoing support. Although mentor training alone does not guarantee

11 successful mentorships (Chambers, 2015), it is important to set clear objectives and

12 enhance role clarity (Lyle \& Cushion, 2017). At present, mentor training rarely extends

13 beyond episodic workshops (Griffiths, 2015), and may function as a mechanism to

14 reproduce organisational beliefs of 'good' mentoring to structure mentor practice (Leeder

$15 \&$ Cushion, 2019). Whilst the training sports coach mentors receive is often absent or

16 lacking in depth, the initial recruitment is also a concern. The recruitment process of

17 mentors can be best described as loose and haphazard (Chambers, 2015), with individuals

18 often recruited because they are simply enthusiastic, alongside exemplifying the right

19 attitude (Chambers, 2015; Jones et al., 2009). Moreover, formalised mentoring

20 programmes are often driven by institutional agendas (Leeder \& Cushion, 2019; Sawiuk

21 et al., 2018), hence, mentors might be recruited due to their portrayed acceptance of the

22 employing GB's beliefs and values (Leeder, Russell, \& Beaumont, 2019).

Practical coaching experience and being a highly qualified coach have also been

24 reported as desirable prerequisites to becoming an effective mentor (Leeder, 2019b).

25 Indeed, Bloom (2013) argued that sports coach mentors should be knowledgeable, whilst 
1 also possessing the right amount of social, cultural, and symbolic capital (through

2 experience and qualifications) to obtain respect from their mentees (Cushion, 2015; Jones

3 et al., 2009). Within Leeder's (2019b) research, a distinct divide was present between

4 mentors who believed capital in the form of coaching qualifications and experience was

5 required to become an effective mentor, in contrast to mentors who attempted to valorise

6 capital as naturalised traits. Despite these contrasting perspectives, the coach learning

7 literature has suggested that once coaches reach a certain level of expertise, mentoring

8 novice coaches becomes a seamless and natural transition (e.g. Bloom et al., 1998;

$9 \quad$ Fairhurst et al., 2017).

\section{Problematising sports coach mentor development}

11 The coach-to-mentor transition is portrayed as natural and somewhat inevitable within

12 sports coaching, with individuals finding themselves in mentoring positions without

13 realising, and more importantly, without training (Cushion, 2015). Through discourse,

14 mentors are positioned as 'educators' rather than 'learners', which often justifies the

15 limited support they receive and reinforces the importance of experiential learning 'on

16 the job' (Achinstein \& Athanases, 2006; Leeder et al., 2019). Within formalised sports

17 coach mentoring, it would appear GBs inherently 'trust' their mentors to do the 'right

18 thing' without significant guidance, due to mentor recruitment being grounded upon the

19 embodiment and portrayal of desired beliefs (Leeder et al., 2019). However, assuming

20 coaching experience or embodiment of a GB's normative beliefs will naturally lead to

21 successful mentoring poses challenges. Nash and McQuade (2015) have cautioned quite

22 succinctly that despite good intentions, not all coaches should be mentors, and that an

23 array of interpersonal skills and transformative training is necessary.

Despite evident problems with the recruitment and training of sports coach

25 mentors, the literature base which specifically examines the learning and development of 
1 these individuals is limited. Koh, Ho, and Koh (2017) explored the developmental

2 experiences of basketball coach mentors, with their findings suggesting that prior

3 experiences as a coach alongside exposure to other mentors influenced the development

4 of mentoring knowledge, whilst self-directed learning helped mentors to enhance their

5 practice. More recently, research has begun to demonstrate the substantial influence of

6 wider mentoring experiences throughout a mentor's life course (Leeder, 2019b). The

7 development of these dispositions will impact on how a sports coach mentor elects to

8 engage with mentor training content, in addition to their interactions with other mentors

9 in the workplace (Leeder et al., 2019). Based upon this body of work, it would seem sports

10 coach mentor learning and development are structured by individual, contextual, and

11 cultural factors which inform future mentoring practice (Koh et al., 2017; Leeder, 2019b;

12 Leeder \& Cushion, 2019).

13 Setting a new agenda: Researching sports coach mentor development

14 Sports coach mentors are involved in multiple networks of learning throughout their role

15 (Potrac, 2016), however, at present we know little about how these influence mentoring

16 practice. Thus, future research into sports coach mentoring must challenge the distorted

17 and overlooked aspects of learning to mentor by revealing the "essential social and

18 relational complexities" inherent within the learning process (Potrac, 2016, p. 84). The

19 literature to date has presented sports coach mentor learning as an idiosyncratic process

20 (Koh et al., 2017; Leeder, 2019b, Leeder et al., 2019). In following this stance, researchers

21 should continue to explore how individual (past experiences), contextual (coaching

22 domain), and cultural (organisations) elements impact upon the development of

23 dispositions towards mentoring practice. Moreover, positioning mentors as 'learners'

24 may help to unearth the reciprocal benefits and learning available for sports coaches who

25 perform a mentoring role (Achinstein \& Athanases, 2006). 
Research should investigate how coaches are recruited and trained as mentors

2 within different contexts, by different organisations, to work with coaches of different

3 domains. Researchers might consider moving closer to the site of mentor development

4 through longitudinal immersion and ethnographic observations of mentor training

5 (Cushion, 2014), to help appreciate mentor learning as a multifaceted interaction between

6 individual, context, and culture (Koh et al., 2017). The exploration of innovative mentor

7 training initiatives, alongside the construction of legitimate knowledge, is required to

8 enhance the professional learning of sports coach mentors. For example, individuals

9 might wish to engage with transdisciplinary research approaches, where researchers and

10 practitioners from different fields collaborate over a set period to develop conceptual and

11 methodological frameworks, potentially resulting in new theoretical approaches (Polk,

12 2014). Whilst the benefits of cross-sport and non-sport mentoring have recently been

13 reported (Sawiuk et al., 2017), perhaps now is the time to bring together mentoring

14 researchers and practitioners from multiple disciplines, to develop a practice-driven

15 conceptual framework for mentor education and training, to avoid superficial and

16 uncritical initiatives.

17 Gender and visible role models in sports coach mentoring: 'You can't be what you

18 can't see'

19 Gender and coach education

20 Scholars continue to problematise formal coach education, for example the entrenched

21 in-gendered discourse which frequently 'others' and disadvantages the minority (Lewis,

22 Roberts, Andrews, \& Sawiuk, 2020). The problematic underrepresentation of women in

23 sports coaching is well documented (Norman \& Rankin-Wright, 2018; Norman, Rankin-

24 Wright, \& Allison, 2018), with sports coaching predominantly a white-male occupation

25 (Norman, 2016). Furthermore, female coaches have reported 'surviving' rather than 
1 thriving within their coaching role (Norman \& Rankin-Wright, 2018), with the value of

2 mentoring for female coach career advancement and personal development being of great

3 significance (Sawiuk \& Groom, 2019).

\section{$4 \quad$ Gender and cross-gender mentoring}

5 Within the broader mentoring literature, the term diversity encompasses cross-gender

6 (male-female dyads) and cross-cultural (international mentor or mentee) dyads, alongside

7 cross-race (ethnic minority mentee) dyads. Ragins (1997) has highlighted diverse

8 mentorships where individuals possess different characteristics, for example race,

9 ethnicity, gender, sexual orientation, class, religion, or disability, which have become key

10 for underrepresented mentee career success (Bearman, Beard, Hunt, \& Crosby, 2007).

11 Career progression for women into management roles has often been prevented by a

12 'glass ceiling' (Bearman et al., 2007). This notion in academia, business, and education

13 has been redefined as a concrete ceiling, which Bearman et al. (2007, p. 386) describe as

14 "an impermeable barrier that keep women and BAME people effectively locked out of

15 the corridors of power in organisations". Unsurprisingly within sports coaching, Norman

16 and colleagues (2018) suggest female coaches and coach developers feel as though a

17 concrete ceiling exists and is preventing their career advancement.

Mentors tend to be white males in positions of power, with female mentees

19 reporting a greater number of promotions when they have their support (Ragins, 1997).

20 A 'masculine hegemony' environment exists, where women in positions of power are

21 absent (Norman et al., 2018). Therefore, perhaps mentorships can support women in

22 climbing these 'greasy poles', with female mentees tending to prefer female mentors who

23 can help them to make sense of 'what works for me?' (Sawiuk \& Groom, 2019). Male

24 mentors in a cross-gender mentorship can pose several problems, such as contrasting

25 personalities or work style, being overpowering and overprotective, or having restricted 
1 accessibility (Murphy \& Kram, 2014; Sawiuk \& Groom, 2019). For cross-gender

2 mentorship success, there must be similarities between the mentor and mentee, which

3 enables both to 'see themselves' in the other. Given the reported external barriers,

4 including unequal competence perception of men and women, homologous reproduction

5 hiring (e.g. employing similar coaches), homophobia, and a disconcerting lack of female

6 mentors and role models (Norman, 2016), successful cross-gender mentorship appears

7 idealistic for diverse and underrepresented groups within sports coaching.

8 Within sports coaching, LaVoi and Dutove (2012) and LaVoi (2016) have

9 recently utilised an ecological systems theory (EST) model to further understand the

10 barriers and facilitators for women coaches within mentoring relationships. Indeed,

11 mentoring can be considered an important vehicle for women coach development, with

12 recent research identifying the potential benefits mentoring has (Banwell, Kerr, \&

13 Stirling, 2020; Banwell et al., 2019). However, mentoring for women coaches can be

14 problematic, with accusations of special treatment and fast-tracked career advancement

15 being reported (Banwell et al., 2020). Whilst some of the benefits and challenges of 16 mentorship for female coaches have been identified, Banwell et al. (2019) have cautioned

17 that more scholarly work is needed to explore gender-based differences, which includes

18 mentoring outcomes and optimal support within both male-mentor female-mentee and

19 female-mentor female-mentee mentorships.

\section{Mentoring, role models, and underrepresented groups}

21 Gibson (2004) defined role model as a cognitive construction based on the attributes of 22 people in social roles which an individual perceives to be similar to themselves and 23 desires to increase their perceived similarity by emulating those attributes, behaviours or 24 values. Role models provide three interrelated functions: to provide learning; to motivate and inspire; and to help an individual define their self-concept (Sawiuk \& Groom, 2019). 
1 LaVoi (2016) recommends female coaches need to 'see' and 'interact' with supportive

2 female coach role models, in the form of friendship, networking and mentorship, to

3 progress their careers and survive the male dominated world of sports coaching. This

4 recommendation is supported by Sawiuk and Groom (2019), where being around

5 supportive role model female coach mentors helped a high-performance female coach

6 advance her career and deal with challenging scenarios e.g. decontextualised coach

7 education. Here, the mentee accessed different knowledge from mentors, such as

8 emotional intelligence and tactical strategies, which helped her to develop knowledge-in-

9 action and increased self-confidence through practical observations.

10 Within effective mentorship, Kram's (1985) seminal work on mentor role

11 function consists of psychosocial (e.g. role modelling, friendship, acceptance,

12 counselling) and career-related (challenging tasks, exposure, protection, sponsorship,

13 coaching, knowledge, networking) functions. The purpose of the psychosocial mentor

14 function is to enhance a mentee's sense of competence, identity, self-worth, and

15 effectiveness in a professional role and beyond, through mentorship grounded in a strong

16 emotional bond with high levels of trust (Kram, 1985), with role modelling the most

17 frequently reported psychosocial function. Consciously or unconsciously, mentor role

18 modelling helps the mentee emulate the mentor's attitudes, values, and behaviours

19 (Ramaswami \& Dreher, 2007), although it is important for a mentee to identify multiple

20 role models rather than searching for a 'whole' role model. Drawing upon Bandura,

21 Sawiuk and Groom (2019) argued role models help shape and influence a mentee's self-

22 identification and motivational aspects of personality. However, the extent to which a

23 mentee will self-actualise (see current and ideal self in the mentor's practice) will differ,

24 with the mentee making informed decisions on which aspects of their mentor to embrace

25 and reject (Sawiuk \& Groom, 2019). 


\section{Setting a new agenda: Gender, role models, and underrepresented groups}

2 The importance of female coaches, mentors or developers as visible and accessible role

3 models cannot be underestimated as an imperative aspect of female coach development

4 (Sawiuk \& Groom, 2019). Research must contribute to challenging the outdated gender

5 stereotypes about women and leadership (LaVoi, 2016), and more specifically "interrupt

6 the downward transmission of pedagogy centred on hegemonic masculinity"

7 (O’Callaghan, 2015, p. 72). Future research on female mentees and mentors might

8 consider adopting a feminist informed methodological approach which aims to

9 academically explore lived experiences of women's voices and issues, with the aim of

10 challenging inequality (Cooky, 2016). Unfortunately, at present there is a dearth of

11 empirical research in the field of sports coaching that explores the concepts of gender,

12 cross-gender, role models or underrepresented groups (race and ethnicity) within a

13 mentoring context. O'Callaghan's (2015) chapter has illuminated some of the

14 disconcerting challenges within mentorships, for example favourable treatment of the

15 dominant culture, stereotyping, and racism (from a subtle undertone to deliberate racial

16 harassment). Moreover, diversity within the mentor workforce will enhance a mentee's

17 ability to 'imagine themselves there' through bespoke, sensitive, and inspirational

18 mentoring practice (O’Callaghan, 2015; Sawiuk \& Groom, 2019). Methodologically,

19 researchers might further consider the use of phenomenological (Clark, Ferkins, Smythe,

$20 \&$ Jogulu, 2018), case study, or narrative enquiry (Hodge \& Sharp, 2016). These

21 approaches can help to explore the specific temporal complexities from a lived experience

22 of a phenomenon (individual, dyad, constellation, group, sport, organisation), focusing

23 on underrepresented group mentoring for career progression.

Lefebvre and colleagues' (2020) work identified Kram (1985) as the most widely 
1 insight, perhaps it is time to further our understanding and go beyond Kram's (1985)

2 workplace mentoring theory. Coaching scholars must move towards a contextualised

3 reconceptualisation of Kram's ideals on mentor role function and types of support, for

4 example career-related, psychosocial and role modelling functions. Furthermore, we

5 must consider which mentor support functions might be more appropriate for a mentee

6 coach within a specific coaching context (participation, development, or elite). Research

7 should explore how holistic demands (technical, tactical, physical, social, psychological)

8 interconnect with pedagogy (behaviour, philosophy, relationships, learning) and

9 multidisciplinary components (performance analysis, recruitment, strength and

10 conditioning) to support a novice coach's or a high-performance coach's bespoke needs.

\section{Concluding thoughts and steps forward}

12 This article has reviewed the contemporary sports coach mentoring literature by focusing 13 on four significant areas of interest: (1) A sociocultural analysis of sports coach 14 mentorship; (2) multiple-mentors and developmental networks; (3) developing sports 15 coach mentors; and (4) gender and role models. By reviewing the existing literature, we 16 argue future research should continue to embrace interpretive sociological frameworks, 17 investigate the utility of multiple-mentors, critically analyse mentor training provision, 18 and challenge problematic assumptions in relation to gender and role modelling within 19 sports coach mentorship. Whilst the four identified areas are by no means an exhaustive 20 list, this article significantly contributes to the sports coach mentoring literature by 21 building upon Jones and colleagues' (2009) original foundations and shaping future 22 research endeavours in sports coach mentoring, ensuring the practice can become more 23 clearly conceptualised and understood as empirical evidence begins to increase. We acknowledge a number of reviews into sports coach mentorship are present within the literature (e.g. Bloom, 2013; Fraina \& Hodge, 2020; Jones et al., 2009; 
1 Lefebvre et al., 2020), however, these tend to focus on wider research from broader

2 domains (e.g. health care, education, and business), merely highlighting 'take home

3 messages' for the sports coaching field to contemplate. In contrast, this article has

4 discussed the contemporary trends within the sports coach mentoring literature and

5 illuminated areas worthy of further exploration, whilst outlining novel methodological

6 approaches for researchers to adopt. In doing so, we have provided a concise start point

7 for scholars and students who may wish to investigate and critique the nuances of sports

8 coach mentorship. Moreover, we believe this work can significantly inform both GBs and

9 sports coach mentors with the design and delivery of mentoring initiatives by encouraging

10 critical reflection on their current beliefs, practices, and perceptions. Thus, in looking

11 back, this article can help sports coach mentorship take a critical step forward within both

12 academia and practice.

Problematically, despite the associated merit of mentoring for coach development,

14 little evidence connects engagement with mentoring to a change in coaching practice.

15 Therefore, the impact and evaluation of formal coach mentoring programmes is worthy

16 of increased consideration. More specifically, areas such as structure and evaluation,

17 successful achievement of purpose, and the role of the programme director warrant

18 further investigation. There is a lack of evaluation-based research exploring sports coach

19 mentoring programmes within the literature, with indicators of effectiveness absent at

20 present (Bloom, 2013). This shortfall needs to be addressed to help provide further

21 research evidence of mentoring practice, as the current research landscape falls short of

22 robust evaluation and detailed analyses relating to mentoring's impact (Cushion, 2015).

23 Furthermore, exploration of sports coach mentoring should be extended to mentee-mentor

24 career outcomes and the role of gender and cross-gender (Banwell et al., 2019), in

25 addition to the influence of technology on the mentoring relationship (Grant et al., 2020). 
We encourage scholars to be brave in their approach to researching sports coach

2 mentoring by adopting methodologies which go beyond description, unearthing the

3 multifaceted, contested, and concealed complexities of mentorship. Recently, conceptual

4 grounded theories have been developed to understand the delivery of performance

5 analysis (Groom, Cushion, \& Nelson, 2011) and sports coaches' professional learning

6 (Stodter \& Cushion, 2017). We believe that for sports coach mentoring practice to take a

7 step forward, a substantive grounded theory is required to understand how both mentors

8 and mentees construct and make sense of the mentoring process.

9 Currently, empirical studies investigating sports coach mentoring have utilised a

10 quantitative approach (e.g. Schempp et al., 2016), which has tended to present mentoring

11 as a linear process, where a set number of 'predictable' mentor functions exist.

12 Nonetheless, Jones et al. (2009, pp. 276-277) previously argued that "insightful

13 qualitative observations perhaps complemented by reflective, in-depth interviews need to

14 be engaged with". Therefore, researchers could begin to utilise more exploratory,

15 conjectural, and original research methods when investigating sports coach mentorship

16 (Jones, 2019), adopting a multiple-method approach to capture the 'complete' mentoring

17 picture. Such examples of innovative qualitative studies into sports coach mentoring

18 exist, utilising both autoethnography and narrative ethnography (e.g. Zehntner \&

19 McMahon, 2014, 2019). However, in building upon the suggestions of Voldby and Klein-

20 Døssing (2019) within coach education, sports coach mentoring researchers might wish

21 to consider the use of action research in order to co-create practice-based knowledge

22 between GBs, mentors, mentees, and scholars. Well-designed action research projects

23 within sports coach mentoring will influence multiple levels of practice rather than

24 producing generic knowledge (Elliott, 1991); for example the development of enhanced 
1 mentor training by GBs, improved pedagogies adopted by mentors, and alterations to

2 mentee coaching practice (Voldby \& Klein-Døssing, 2019).

3 In concluding this article, despite increased academic work on mentoring practice

4 since Jones and colleagues' (2009) seminal review, gaps in our knowledge are still

5 evident, thus making it difficult to decipher what works and why within sports coach

6 mentoring relationships. It is hoped this look back and review of contemporary sports

7 coach mentoring literature has sparked curiosity within coaching scholars' minds to

8 address the newly set research agendas and beyond, helping to take a step forward in our

9 quest to both comprehend and conceptualise sports coach mentorship.

\section{Acknowledgements}

11 We would like to thank the two reviewers for their useful feedback on earlier drafts of 12 this manuscript. 
2 Achinstein, B., \& Athanases, S. Z. (2006). Mentors in the making: Developing new 3 leaders for new teachers. New York: Teachers College Press.

4 Bailey, J., Jones, R. L., \& Allison, W. (2019). Sports coaches' mentorship: Experience 5 and a suggested future framework. European Journal of Human Movement, 43, 67-85.

6 Banwell, J., Stirling, A., \& Kerr, G. (2019). Towards a process for advancing women in 7 coaching through mentorship. International Journal of Sports Science \& Coaching, 8 14(6), 703-713.

9 Banwell, J., Kerr, G., \& Stirling A. (2020). Benefits of a female coach mentorship 10 programme on women coaches' development: An ecological perspective. Sports 11 Coaching Review, 1-23.

12 Baugh, S. G., \& Scandura, T. A. (1999). The effects of multiple mentors on protégé 13 attitudes toward the work setting. Journal of Social Behaviour and Personality, 14(2), $14503-521$.

15 Bearman, S., Beard, S. B., Hunt, L., \& Crosby, F. J. (2007). New directions in mentoring. 16 In T. D. Allen \& L. T. Eby (Eds.), The Blackwell handbook of mentoring: A multiple 17 perspectives approach (pp. 373-395). United Kingdom: Blackwell Publishing Ltd.

18 Bloom, G. A. (2013). Mentoring for sport coaches. In P. Potrac, W. Gilbert, \& J. Denison 19 (Eds.), Routledge handbook of sports coaching (pp. 476-485). London: Routledge.

20 Bloom, G. A., Durand-Bush, N., Schinke. R. J., \& Salmela, J. H. (1998). The importance 21 of mentoring in the development of coaches and athletes. International Journal of Sport 22 Psychology, 29, 267-281.

23 Bourdieu, P. (1990). The logic of practice. Cambridge: Polity Press.

24 Chambers, F. C. (2015). Mentoring in physical education and sports coaching. London: 25 Routledge.

26 Chambers, F. C. (2018). Learning to mentor in sports coaching: A design thinking 27 approach. London: Routledge.

28 Clark, K., Ferkins, L., Smythe, L., \& Jogulu, U. (2018). Valuing the lived experience: A 29 phenomenological study of skiing. Sport in Society, 21(2), 283-301.

30 Colley, H. (2003). Mentoring for social inclusion: A critical approach to nurturing 31 mentoring relationships. London: Routledge.

32 Cooky, C. (2016). Feminisms. In B. Smith \& A. Sparkes (Eds.), Routledge handbook of 33 qualitative research in sport and exercise (pp. 75-87). London: Routledge.

34 Cushion, C. J. (2014). Ethnography. In L. Nelson, R. Groom, \& P. Potrac (Eds.), Research 35 methods in sports coaching (pp. 171-181). London: Routledge.

36 Cushion, C. (2015). Mentoring for success in sport coaching. In F. C. Chambers (Ed.), 37 Mentoring in physical education and sports coaching (pp. 155-162). London: Routledge. 
1 Cushion, C. J., Armour, K. M., \& Jones, R. L. (2003). Coach education and continuing 2 professional development: Experience and learning to coach. Quest, 55, 215-230.

3 Darwin, A. (2000). Critical reflections on mentoring in work settings. Adult Education 4 Quarterly, 50(3), 197-211.

5 Dawson, P. (2014). Beyond a definition: Toward a framework for designing and 6 specifying mentoring models. Educational Researcher, 43(3), 137-145.

7 De Janasz, S. C., \& Sullivan, S. E. (2004). Multiple mentoring in academe: Developing 8 the professorial network. Journal of Vocational Behavior, 64(2), 263-283.

9 Elliott, J. (1991). Action research for educational change. Milton Keynes: Open 10 University.

11 Fraina, M., \& Hodge, S. R. (2020). Mentoring relationships among athletes, coaches, and 12 athletic administrators: A literature review. Journal for the Study of Sports and Athletes 13 in Education, 14(2), 140-164.

14 Fairhurst, K. A., Bloom, G. A., \& Harvey, W. J. (2017). The learning and mentoring 15 experiences of Paralympic coaches. Disability and Health Journal, 10, 240-246.

16 Foucault, M. (1979). Discipline and punish: The birth of the prison. New York: Vintage 17 Books.

18 Gibson, D. E. (2004). Role models in career development: New directions for theory and research. Journal of Vocational Behaviour, 65, 134-156.

20 Grant, M. A., Bloom, G. A., \& Lefebvre, J. S. (2020). Lessons learned: Coaches' 21 perceptions of a pilot e-mentoring programme. International Sport Coaching Journal, $227(1), 22-30$.

23 Griffiths, M. (2015). Training coaches as mentors. In F. C. Chambers (Ed.), Mentoring 24 in physical education and sports coaching (pp. 163-171). London: Routledge.

Griffiths, M., \& Armour, K. M. (2012). Mentoring as a formalised learning strategy with 26 community sports volunteers. Mentoring and Tutoring: Partnerships in Learning, 20(1), $27 \quad 151-173$.

Groom, R., \& Sawiuk, R. (2018). Making the transition from the UEFA Advanced 29 Licence to the UEFA Professional Licence (or not). In F. C. Chambers (Ed.), Learning to 30 mentor in sports coaching: A design thinking approach (pp. 56-76). London: Routledge.

31 Groom, R., Cushion, C., \& Nelson, L. (2011). The delivery of video-based performance 32 analysis by England youth soccer coaches: Towards a grounded theory. Journal of 33 Applied Sport Psychology, 23(1), 16-32.

34 Higgins, M. C., \& Kram, K. E. (2001). Reconceptualizing mentoring at work: A 35 developmental network perspective. Academy of Management Review, 26, 264-288. Higgins, M. C., Chandler, D. E., \& Kram, K. E. (2007). Developmental initiation and developmental networks. In B. R. Ragins \& K. E. Kram (Eds.), The handbook of 38 mentoring at work: Theory, research and practice (pp. 349-372). Thousand Oaks, CA: 39 SAGE. 
1 Hodge, K., \& Sharp, L. (2016). Case studies. In B. Smith \& A. Sparkes (Eds.), Routledge

2 handbook of qualitative research in sport and exercise (pp. 62-74). London: Routledge.

3 Jones, R. (2019). Sport coaching research: A brief look around and forward. In C. L. T.

4 Corsby \& C. N. Edwards (Eds.), Exploring research in sports coaching and pedagogy:

5 Context and contingency (pp. 153-158). Newcastle upon Tyne: Cambridge Scholars

6 Publishing.

7 Jones, R. L., Harris, R., \& Miles, A. (2009). Mentoring in sports coaching: A review of 8 the literature. Physical Education and Sport Pedagogy, 14(3), 267-284.

9 Kemmis, S., Heikkinen, H. L. T., Fransson, G., Aspfors, J., \& Edwards-Groves, C. 10 (2014). Mentoring of new teachers as a contested practice: Supervision, support and 11 collaborative self-development. Teaching and Teacher Education, 43, 154-164.

12 Koh, K. T., Ho, X. Y., \& Koh, Y. (2017). The developmental experiences of basketball 13 mentor coaches. International Journal of Sports Science \& Coaching, 12(4), 520-531.

14 Kram K. E. (1983). Phases of the mentoring relationship. Academy of Management 15 Journal, 26, 608-625.

16 Kram, K. E. (1985). Mentoring at work: Developmental relationships in organisational 17 life. Glenview, IL: Scott Foresman.

18 LaVoi, N. M. (2016). Concluding thoughts: Strategies for change for women coaches. 19 In N. M. LaVoi (Ed.), Women in sports coaching (pp. 257-260). London: Routledge.

20 LaVoi, N. M., \& Dutove, J. K. (2012). Barriers and supports for female coaches: An 21 ecological model. Sports Coaching Review, 1(1), 17-37.

Leeder, T. (2019a). Foucault and pastoral power: Implications for formalised sports coach mentoring. In C. L. T. Corsby \& C. N. Edwards (Eds.), Exploring research in sports coaching and pedagogy: Context and contingency (pp. 111-120). Newcastle upon Tyne: 25 Cambridge Scholars Publishing.

Leeder, T. (2019b). "You need to be a certain kind of person": Learning to 'become' a community coach mentor. In L. Gale \& B. Ives (Eds.), Sports coaching in the community: 28 Developing knowledge and insight (pp. 33-48). Manchester: Manchester Metropolitan 29 Publishers.

30 Leeder, T., \& Cushion. C. (2019). The reproduction of 'coaching culture': A 31 Bourdieusian analysis of a formalised coach mentoring programme. Sports Coaching 32 Review, 1-23.

33 Leeder, T. M., Russell, K., \& Beaumont, L. (2019). "Learning the hard way": 34 Understanding the workplace learning of sports coach mentors. International Sport 35 Coaching Journal, 6(3), 263-273.

36 Lefebvre, J. S., Bloom, G. A., \& Loughead, T. M. (2020). A citation network analysis of 37 career mentoring across disciplines: A road map for mentoring research in sport. 38 Psychology of Sport \& Exercise, 49, 1-11. 
1 Lewis, C. J., Roberts, S. J., Andrews, H., \& Sawiuk, R. (2020). A creative writing case 2 study of gender-based violence in coach education: Stacey's Story. Women in Sport and 3 Physical Activity Journal, 28, 72-80.

4 Lyle, J., \& Cushion, C. (2017). Sports coaching concepts: A framework for coaching 5 practice (2nd ed.). London: Routledge.

6 MacLaren, J. (2018). Supporting nurse mentor development: An exploration of 7 developmental constellations in nursing mentorship practice. Nurse Education in 8 Practice, 28, 66-75.

9 McMahon, J. (2016). Creative analytical practices. In B. Smith \& A. Sparkes (Eds.), 10 Routledge handbook of qualitative research in sport and exercise (pp. 302-315). London: 11 Routledge.

12 Murphy, W., \& Kram, K. E. (2014). Strategic relationships at work: Creating your circle 13 of mentors, sponsors, and peers for success in business and life. New York: McGraw Hill 14 Education.

15 Nash, C., \& McQuade, S. (2015). Mentoring as a coach development tool. In C. Nash 16 (Ed.), Practical sports coaching (pp. 206-223). London: Routledge.

17 Newby, T. J., \& Heide, A. (2013). The value of mentoring. Performance Improvement 18 Quarterly, 26(2), 141-158.

19 Norman, L. (2016). Is there a need for coaches to be more gender responsive? A review 20 of the evidence. International Sport Coaching Journal, 3(2), 192-196.

21 Norman, L., \& Rankin-Wright, J. (2018). Surviving rather than thriving: Understanding 22 the experiences of women coaches using a theory of gendered social well-being. 23 International Review for the Sociology of Sport, 53(4), 424-450.

24 Norman, L., Rankin-Wright, A. J., \& Allison, W. (2018). "It's a concrete ceiling; It's not 25 even glass": Understanding tenets of organizational culture that supports the progression of women as coaches and coach developers. Journal of Sport and Social Issues, 42, 393414.

28 O'Callaghan, L. (2015). Mentoring, 'race' and ethnicity. In F. C. Chambers (Ed.), 29 Mentoring in physical education and sports coaching (pp. 66-74). London: Routledge.

30 Phoenix, C., \& Rich, E. (2016). Visual research methods. In B. Smith \& A. Sparkes 31 (Eds.), Routledge handbook of qualitative research in sport and exercise (pp. 139-151). 32 London: Routledge.

33 Polk, M. (2014). Achieving the promise of transdisciplinarity: A critical exploration of 34 the relationship between transdisciplinary research and societal problem solving. 35 Sustainability Science, 9, 439-451.

36 Potrac, P. (2016). Delivering the FA Grassroots Club Mentor Programme: Mentors' 37 experience of practice. In W. Allison, A. Abraham, \& A. Cale (Eds.), Advances in coach 38 education and development: From research to practice (pp. 76-86). London: Routledge. 
1 Ragins, B. R. (1997). Diversified mentoring relationships in organizations: A power 2 perspective. Academy of Management Review, 22, 482-521.

3 Ramaswami, A., \& Dreher, G. F. (2007). The benefits associated with workplace 4 mentoring relationships. In T. D. Allen \& L. T. Eby (Eds.), The Blackwell handbook of 5 mentoring: A multiple perspectives approach (pp. 211-231). United Kingdom: Blackwell 6 Publishing Ltd.

7 Sawiuk, R., \& Groom, R. (2019). Mentoring in coach education: The importance of role 8 models, context and gender. In E. Cope \& M. Partington (Eds.), Sports coaching: A 9 theoretical and practical guide (pp. 55-68). London: Routledge.

10 Sawiuk, R., Taylor, W. G., \& Groom, R. (2017). An analysis of the value of multiple 11 mentors in formalised elite coach mentoring programmes. Physical Education and Sport 12 Pedagogy, 22(4), 403-413.

13 Sawiuk, R., Taylor, W. G., \& Groom, R. (2018). Exploring formalised elite coach 14 mentoring programmes in the UK: 'We've had to play the game'. Sport, Education and 15 Society, 23(6), 619-631.

16 Schempp, P. G., Elliott, J., McCullick, B. A., Laplaca, D., \& Berger, B. (2016). Mentors' 17 roles in basketball coaching. International Journal of Sport Psychology, 47, 1-15.

18 Stodter, A., \& Cushion, C. J. (2017). What works in coach learning, how, and for whom? 19 A grounded process of soccer coaches' professional learning. Qualitative Research in 20 Sport, Exercise and Health, 9(3), 321-338.

21 Trudel, P., \& Gilbert, W. (2006). Coaching and coach education. In D. Kirk, D. 22 Macdonald, \& M. O'Sullivan (Eds.), Handbook of research in physical education (pp. 23 516-539). London: SAGE.

24 Voldby, C. R., \& Klein-Døssing, R. (2019). "I thought we were supposed to learn how to 25 become better coaches": Developing coach education through action research. 26 Educational Action Research, 1-20.

27 Wiser, M. C. (2018). Opportunities to interpret: A methodological discussion of insider 28 research, perceptions of the researcher, and knowledge production. Sport in Society, 29 21(2), 215-225.

30 Zehntner, C., \& McMahon, J. A. (2014). Mentoring in coaching: The means of correct 31 training? An autoethnographic exploration of one Australian swimming coach's 32 experiences. Qualitative Research in Sport, Exercise and Health, 6(4), 596-616.

33 Zehntner, C., \& McMahon, J. (2019). Power and knowledge in a coach mentoring 34 program. Sports Coaching Review, 8(1), 62-82. 